\title{
Aplicativos móveis para a saúde e o cuidado de idosos
}

\section{Mobile applications for the health and care of elderly}

\section{Aplicaciones móviles para la salud y el cuidado de los ancianos}

Diane Nogueira Paranhos Amorim ${ }^{1, a}$

diannenogueira@hotmail.com | https://orcid.org/0000-0002-5362-5747

Luisa Veríssimo Pereira Sampaio ${ }^{1, a}$

verissimo.luisa@hotmail.com | https://orcid.org/o000-0003-1457-9431

Gustavo de Azevedo Carvalho ${ }^{1, b}$

carvalhobsb@hotmail.com | https://orcid.org/oooo-0003-4155-1514

Karla Helena Coelho Vilaça ${ }^{1, c}$

kavilaca@yahoo.com.br | https://orcid.org/oooo-0002-4937-2396

\footnotetext{
${ }^{1}$ Universidade Católica de Brasília. Brasília, DF, Brasil.

a Mestrado em Gerontologia pela Universidade Católica de Brasília.

b Doutorado em Ciências da Saúde pela Universidade de Brasília.

c Doutorado em Investigação Biomédica pela Universidade de São Paulo.
}

\section{Resumo}

O crescente uso de smartphones, aliado ao envelhecimento populacional, fez surgirem no mercado diversos aplicativos voltados para o público idoso. Diante dessa realidade, o objetivo do estudo aqui apresentado foi descrever os aplicativos direcionados à saúde e ao cuidado de idosos. Realizou-se uma busca de aplicativos em smartphones com sistema operacional Android e iOS. Os descritores utilizados na busca foram: 'idoso', 'saúde do idoso', 'envelhecimento', 'elderly' e 'salud de los ancianos'. Foram encontrados 25 aplicativos que abrangem três temas: saúde dos idosos, cuidado de idosos e informações sobre a saúde e o cuidado de idosos. Os aplicativos objetivam a prática de exercício físico, a prevenção ou detecção de quedas, a estimulação cognitiva, a busca de profissionais ou serviços, o auxílio ao cuidado de idosos e a divulgação de informações sobre saúde e sobre doenças e tratamentos. Esses recursos podem trazer grande contribuição à saúde e ao aperfeiçoamento do cuidado ao idoso, sendo um instrumento de monitoramento, informação e promoção de hábitos saudáveis.

Palavras-chave: idoso; saúde do idoso; aplicativos móveis; smartphone; tecnologia biomédica, saúde móvel. 


\begin{abstract}
The increasing use of smartphones, coupled with the aging of the population, has brought to the market several applications aimed at the elderly public. Faced with this reality, the objective of the study presented on this article was to describe the applications directed to the health and care of the elderly. We searched for applications on smartphones with Android and iOS operating systems. The descriptors used in the search were: 'idoso', 'saúde do idoso', 'envelhecimento', 'elderly' and 'health of the elderly'. 25 applications covering three themes were found: elderly health, elderly care, and health and care information about the elderly. The applications aim the practice of physical exercise, the prevention or detection of falls, the cognitive stimulation, the search for professionals or services, the assistance of elderly care and the dissemination of information on health and on diseases and treatments. Applications for smartphones can make a great contribution to health and the improvement of elderly care, being an instrument for monitoring, information and promotion of healthy habits.
\end{abstract}

Keywords: elderly; elderly health; mobile applications; smartphone; biomedical technology; mobile health.

\title{
Resumen
}

El creciente uso de teléfonos inteligentes, aliado al envejecimiento de la población, hizo que surgiesen en el mercado diversas aplicaciones destinadas al público anciano. Ante esa realidad el objetivo del estudio ahora presentado fue describir las aplicaciones dirigidas a la salud y al cuidado de los ancianos. Se realizó una búsqueda de aplicaciones en teléfonos inteligentes con sistema operativo Android e iOS. Los descriptores utilizados en la búsqueda fueron: 'idoso', 'saúde do idoso', 'envelhecimento', 'elderly' e 'salud de los ancianos'. Fueron encontradas 25 aplicaciones que abarcan tres temas: salud de los ancianos, cuidado de los ancianos y información sobre salud y cuidados de los ancianos. Las aplicaciones objetivan la práctica de ejercicios físicos, la prevención o detección de caídas, la estimulación cognitiva, la búsqueda de profesionales o servicios, la ayuda al cuidado del anciano y la divulgación de información sobre la salud y sobre las enfermedades y los tratamientos. Las aplicaciones para teléfonos inteligentes pueden aportar una gran contribución a la salud y para mejorar el cuidado del anciano, siendo un recurso de vigilancia, información y promoción de hábitos saludables.

Palabras clave: anciano; salud del anciano; aplicaciones móviles; teléfonos inteligentes; tecnología biomédica; salud móvil.

Contribuição dos autores: Diane Nogueira Paranhos Amorim foi responsável pela concepção deste estudo e redação do manuscrito. Luisa Veríssimo Pereira Sampaio foi responsável pela redação do manuscrito. Gustavo de Azevedo Carvalho e Karla Helena Coelho Vilaça foram responsáveis pela revisão crítica e aprovação da versão final a ser publicada.

Declaração de conflito de interesses: Os autores declaram não haver qualquer conflito de interesse.

Fontes de financiamento: Fundação de Apoio à Pesquisa do Distrito Federal (FAP DF). Bolsa de Doutorado do Programa PMD/ UCB/FAPDF 2017, n² 24/2017.

Considerações éticas: não há.

Agradecimentos/Contribuições adicionais: não há.

Histórico do artigo: Submetido: 14.ago.2017 | Aceito: 14.fev.2018 | Publicado: 30.mar.2018.

Apresentação anterior: não houve.

Licença CC BY-NC atribuição não comercial. Com essa licença é permitido acessar, baixar (download), copiar, imprimir, compartilhar, reutilizar e distribuir os artigos, desde que para uso não comercial e com a citação da fonte, conferindo os devidos créditos de autoria e menção à Reciis. Nesses casos, nenhuma permissão é necessária por parte dos autores ou dos editores. 


\section{Introdução}

Os idosos têm se destacado ao longo das décadas por seu crescimento populacional nos mais diversos países. No Brasil, esse crescimento é evidenciado nas projeções que indicam que, após 2030, o grupo de 60 anos ou mais será maior que o grupo de crianças com até 14 anos de idade. Em 2055, a participação de idosos na população total será maior que a de crianças e jovens ${ }^{1}$.

O expressivo aumento da população de idosos acarreta impactos e desafios políticos, socioculturais e econômicos para atender às demandas desse crescente contingente ${ }^{2}$. Uma delas é a participação de forma mais efetiva na sociedade, inclusive nas atividades relacionadas à tecnologia ${ }^{3}$, já que, apesar de haver um aumento do acesso à internet e do uso de tecnologia pelos idosos a cada ano, eles ainda são o grupo populacional mais excluído digitalmente ${ }^{4}$.

Dentre os recursos tecnológicos que despertam o interesse do público idoso, os smartphones têm se destacado por incorporarem, ao celular, funcionalidade de computador, como conexão à internet e possibilidade de uso de aplicativos ${ }^{5}$. Nos Estados Unidos, a porcentagem de idosos que possuíam seu próprio smartphone aumentou de $18 \%$ para $42 \%$ no período de 2013 a $2016^{6}$. No Brasil, o percentual de idosos com acesso à internet passou de 12,6\% em 2013, para 17,4\% em 2015 e, ainda segundo o IBGE7, o dispositivo móvel celular foi o principal meio utilizado nos domicílios para esse acesso. Outra pesquisa com 619 idosos brasileiros revelou que 61,1\% utilizam o smartphone para se comunicarem ${ }^{8}$.

O crescente uso de smartphone, somado ao envelhecimento populacional, provocou o surgimento no mercado de diversos aplicativos voltados para a pessoa idosa ${ }^{9}$, pois, além do fácil acesso à internet e do relativo baixo custo, os smartphones comportam aplicativos de variados temas, inclusive os da área da saúde e de cuidado de idosos, despontando como uma nova ferramenta para melhorar o acesso dessa população à saúde ${ }^{10}$.

Os aplicativos voltados para a saúde e o cuidado de idosos são recursos importantes, visto que essas informações obtidas por meio da internet e outras mídias podem influenciar o estilo de vida, propiciar a detecção precoce de eventuais problemas de saúde e promover o envelhecimento ativo e saudável ${ }^{11}$. Além disso, despertam o interesse e a curiosidade da população idosa, tornando-se um recurso de entretenimento que contribui também para a sua inclusão digital ${ }^{9}$.

Desse modo, esses aplicativos funcionam como estratégias que permitem o empoderamento dos idosos no cuidado da sua própria saúde ${ }^{12}$, além de serem um instrumento de mensuração e diagnóstico para profissionais de saúde ${ }^{13} \mathrm{e}$ de consulta e esclarecimento para familiares.

No estudo de Souza e Silva ${ }^{9}, 46$ aplicativos voltados para a funcionalidade do idoso foram descritos. Eles são uma ferramenta para melhorar a independência de idosos. No Brasil, aplicativos que visam à melhora nas funções cognitivas ${ }^{14} \mathrm{e}$ à identificação rápida de síndromes geriátricas ${ }^{13}$ já foram desenvolvidos. Na Alemanha, um aplicativo voltado para a adesão de pacientes idosos a medicamentos, aumentou objetiva e subjetivamente a adesão de usuários submetidos a tratamento de doença cardíaca coronariana ${ }^{15}$. Assim, esse tipo de programa representa um meio eficaz de atingir o público idoso e de disponibilizar ferramentas que os beneficiam ${ }^{16}$.

Diante desse contexto, o objetivo do presente estudo é descrever os aplicativos móveis, disponíveis em smartphones, voltados para a saúde e o cuidado de idosos. 


\section{Método}

Realizou-se uma busca de aplicativos voltados para a saúde e o cuidado de idosos em smartphones com sistemas operacionais Android e iOS. A busca foi efetuada na Google Play Store, utilizando um aparelho com sistema operacional Android e, na Apple Store, usando um celular com sistema operacional iOS.

No campo de busca dessas lojas específicas, foram digitados para procurar os aplicativos os descritores 'idoso', ‘saúde do idoso', 'envelhecimento', 'elderly' e 'salud de los ancianos'.

Consideraram-se aplicativos voltados para a saúde do idoso aqueles que abordam a promoção da saúde física e cognitiva e/ou a prevenção de condições e de eventos nocivos à saúde do idoso, como quedas, fragilidade e dependência funcional. Consideraram-se aplicativos voltados para o cuidado de idosos aqueles que visam instruir e auxiliar o desempenho da atividade de cuidar do idoso que necessita de ajuda parcial ou total para realizar as atividades diárias de higiene e de autocuidado e/ou aplicativos que realizam uma busca de profissionais ou serviços de saúde.

Todos os aplicativos encontrados por meio dos descritores mencionados tiveram sua descrição lida e foram incluídos na pesquisa de acordo com os seguintes critérios de inclusão: aplicativos sobre saúde e/ou cuidado de idosos nos idiomas português, inglês ou espanhol.

Os critérios de exclusão foram: aplicativos voltados para a vida social do idoso, direcionados para uma doença específica e aqueles voltados ao diagnóstico e à avaliação em saúde.

\section{Resultado e discussão}

Após a busca, foram incluídos na pesquisa 25 aplicativos abrangendo três temas: saúde dos idosos (oito), cuidado de idosos (dez) e informações sobre saúde e cuidados de idosos (sete).

Dentro de cada tema, eles foram divididos de acordo com os seus objetivos. Dos aplicativos voltados para a saúde, três visam à prática de exercício físico (aplicativos 1 a 3), quatro objetivam a prevenção ou detecção de quedas (aplicativos 4 a 7) e um a estimulação cognitiva (aplicativo 8). Dos aplicativos voltados para o cuidado de idosos, quatro auxiliam a busca de profissionais de saúde, cuidadores ou serviços médicos (aplicativos 15 a 18) e seis visam auxiliar diretamente o cuidado de idosos (aplicativos 9 a 14). E dos aplicativos com informações sobre saúde e cuidados de idosos (19 a 25), quatro contém informações sobre saúde, bem-estar e serviços para idosos $(19,20,24,25)$ e três contém informações clínicas sobre avaliação e tratamento/gerenciamento de doenças e agravos $(21,22,23)$ (Quadro 1).

O público-alvo dos aplicativos foram os idosos, seus familiares, cuidadores e profissionais de saúde (Quadro 1). 
Quadro 1. Descrição dos aplicativos voltados para a saúde e o cuidado dos idosos

\begin{tabular}{|c|c|c|c|c|c|c|c|}
\hline $\begin{array}{l}\text { Aplicativo } \\
\text { (língua } \\
\text { em que se } \\
\text { encontra) }\end{array}$ & Categoria & Descrição geral & Funcionalidade & $\begin{array}{l}\text { Termos } \\
\text { relacionados } \\
\text { na busca }\end{array}$ & $\begin{array}{l}\text { Público- } \\
\text { alvo }\end{array}$ & $\begin{array}{l}\text { Sistema } \\
\text { operacional }\end{array}$ & Custo \\
\hline \multicolumn{8}{|c|}{ Aplicativos voltados para a saúde dos idosos } \\
\hline $\begin{array}{l}1 \\
\text { Idoso ativo } \\
\text { (português) }\end{array}$ & $\begin{array}{l}\text { Prática de } \\
\text { exercício físico }\end{array}$ & $\begin{array}{l}\text { Estímulo e } \\
\text { promoção da } \\
\text { prática de exercício } \\
\text { físico para idosos }\end{array}$ & $\begin{array}{l}\text { Orientações } \\
\text { escritas em } \\
\text { vídeos, e áudio } \\
\text { para a prática } \\
\text { de um protocolo } \\
\text { de exercícios } \\
\text { funcionais } \\
\text { para membros } \\
\text { inferiores }\end{array}$ & Idoso & Idosos & Android e iOS & Gratuito \\
\hline $\begin{array}{l}2 \\
\text { Exercício } \\
\text { aptidão sênior } \\
\text { (inglês) }\end{array}$ & $\begin{array}{l}\text { Prática de } \\
\text { exercício físico }\end{array}$ & $\begin{array}{l}\text { Orientações de } \\
\text { exercícios físicos } \\
\text { para melhora das } \\
\text { dores }\end{array}$ & $\begin{array}{l}\text { Contém roteiros } \\
\text { de exercícios } \\
\text { diários com } \\
\text { imagens e } \\
\text { orientações } \\
\text { escritas } \\
\end{array}$ & Idoso & Idosos & Android & Gratuito \\
\hline $\begin{array}{l}3 \\
\text { Senior fitness } \\
\text { workouts } \\
\text { (inglês) }\end{array}$ & $\begin{array}{l}\text { Prática de } \\
\text { exercício físico }\end{array}$ & $\begin{array}{l}\text { Programa de } \\
\text { treinamento } \\
\text { projetado } \\
\text { especifica-mente } \\
\text { para idosos }\end{array}$ & $\begin{array}{l}\text { Instruções } \\
\text { por vídeos } \\
\text { e áudios do } \\
\text { treinamento para } \\
\text { condicionamento } \\
\text { cardiorrespiratório } \\
\text { ganho de massa } \\
\text { e resistência } \\
\text { muscular, } \\
\text { flexibilidade e } \\
\text { equilíbrio }\end{array}$ & $\begin{array}{l}\text { Salud de los } \\
\text { ancianos }\end{array}$ & Idosos & Android & Gratuito \\
\hline $\begin{array}{l}4 \\
\text { Não deixe a } \\
\text { vovó cair } \\
\text { (português) }\end{array}$ & $\begin{array}{l}\text { Prevenção de } \\
\text { quedas }\end{array}$ & $\begin{array}{l}\text { Auxilia a redução } \\
\text { dos riscos } \\
\text { do ambiente } \\
\text { domiciliar que } \\
\text { propiciam a } \\
\text { ocorrência de } \\
\text { quedas }\end{array}$ & $\begin{array}{l}\text { Jogo com o } \\
\text { objetivo de } \\
\text { corrigir erros } \\
\text { que aumentam o } \\
\text { risco de quedas } \\
\text { no domicílio; ao } \\
\text { longo do jogo } \\
\text { informações sobre } \\
\text { riscos domiciliares } \\
\text { são dadas }\end{array}$ & Idoso & $\begin{array}{l}\text { Idosos e } \\
\text { familiares }\end{array}$ & Android & Gratuito \\
\hline $\begin{array}{l}5 \\
\text { Prevenção de } \\
\text { quedas do } \\
\text { idoso } \\
\text { (português) }\end{array}$ & $\begin{array}{l}\text { Prevenção de } \\
\text { quedas }\end{array}$ & $\begin{array}{l}\text { Objetiva prevenir } \\
\text { a ocorrência } \\
\text { de quedas nos } \\
\text { idosos e melhorar } \\
\text { os parâmetros } \\
\text { de fragilidade, } \\
\text { autopercep- } \\
\text { ção da saúde e } \\
\text { medo de cair }\end{array}$ & $\begin{array}{l}\text { Avaliação dos } \\
\text { medicamentos } \\
\text { em uso, doenças } \\
\text { crônicas, } \\
\text { hipotensão } \\
\text { postural, cognição } \\
\text { e humor, } \\
\text { vulnerabilidade do } \\
\text { paciente e riscos } \\
\text { do ambiente } \\
\text { domiciliar. } \\
\text { Orientação para } \\
\text { a prática de } \\
\text { exercício físico }\end{array}$ & $\begin{array}{l}\text { Idoso; salud de } \\
\text { los ancianos; } \\
\text { saúde do idoso }\end{array}$ & $\begin{array}{l}\text { Profissionais } \\
\text { de saúde }\end{array}$ & Android & Gratuito \\
\hline
\end{tabular}




\begin{tabular}{|c|c|c|c|c|c|c|c|}
\hline $\begin{array}{l}\text { Aplicativo } \\
\text { (língua } \\
\text { em que se } \\
\text { encontra) }\end{array}$ & Categoria & Descrição geral & Funcionalidade & $\begin{array}{l}\text { Termos } \\
\text { relacionados } \\
\text { na busca }\end{array}$ & $\begin{array}{l}\text { Público- } \\
\text { alvo }\end{array}$ & $\begin{array}{l}\text { Sistema } \\
\text { operacional }\end{array}$ & Custo \\
\hline $\begin{array}{l}6 \\
\text { Quete caes - } \\
\text { detector caída } \\
\text { (espanhol) }\end{array}$ & $\begin{array}{l}\text { Detector de } \\
\text { quedas }\end{array}$ & $\begin{array}{l}\text { Comunica a } \\
\text { queda do idoso } \\
\text { a um familiar ou } \\
\text { cuidador }\end{array}$ & $\begin{array}{l}\text { Detecta a queda } \\
\text { do idoso (que } \\
\text { deve usar o } \\
\text { celular no bolso) e } \\
\text { envia mensagens } \\
\text { ao familiar ou } \\
\text { cuidador cujo } \\
\text { número do celular } \\
\text { foi cadastrado no } \\
\text { aplicativo }\end{array}$ & $\begin{array}{l}\text { Salud de los } \\
\text { ancianos }\end{array}$ & Idosos & Android & Gratuito \\
\hline $\begin{array}{l}7 \\
\text { Elderly fall alert } \\
\text { (inglês) }\end{array}$ & $\begin{array}{l}\text { Detector de } \\
\text { quedas }\end{array}$ & $\begin{array}{l}\text { Comunica a } \\
\text { queda do idoso } \\
\text { a um familiar ou } \\
\text { cuidador }\end{array}$ & $\begin{array}{l}\text { Detecta a queda } \\
\text { e envia uma } \\
\text { mensagem } \\
\text { ao familiar ou } \\
\text { cuidador cujo } \\
\text { número do celular } \\
\text { foi cadastrado no } \\
\text { aplicativo }\end{array}$ & Elderly & Idosos & Android & $\mathrm{R} \$ 7,49$ \\
\hline $\begin{array}{l}8 \\
\text { Senior games } \\
\text { (português) }\end{array}$ & $\begin{array}{l}\text { Estimula-ção } \\
\text { cognitiva }\end{array}$ & $\begin{array}{l}\text { Atividades de } \\
\text { estímulo cognitivo } \\
\text { para idosos }\end{array}$ & $\begin{array}{l}\text { Oito jogos de } \\
\text { estimulação } \\
\text { cognitiva com } \\
\text { o objetivo de } \\
\text { melhorar a } \\
\text { atenção, foco, } \\
\text { habilidade } \\
\text { matemática, } \\
\text { memória e } \\
\text { associação }\end{array}$ & Idoso & Idosos & iOS & USD 1,99 \\
\hline \multicolumn{8}{|c|}{ Aplicativos voltados para o cuidado de idosos } \\
\hline $\begin{array}{l}9 \\
\text { Guia do } \\
\text { cuidador de } \\
\text { idosos } \\
\text { (português) }\end{array}$ & Cuidado do idoso & $\begin{array}{l}\text { Guia para ajudar } \\
\text { cuidadores e } \\
\text { familiares no } \\
\text { cuidado de idosos } \\
\text { em casa }\end{array}$ & $\begin{array}{l}\text { Conteúdo e } \\
\text { orientações } \\
\text { sobre temas } \\
\text { relacionados } \\
\text { a idosos e } \\
\text { emergências em } \\
\text { saúde, além de } \\
\text { telefones úteis } \\
\text { como do Samu, } \\
\text { do corpo de } \\
\text { bombeiros e da } \\
\text { polícia }\end{array}$ & $\begin{array}{l}\text { Idoso; saúde do } \\
\text { idoso }\end{array}$ & $\begin{array}{l}\text { Cuidadores } \\
\text { de idosos }\end{array}$ & Android & Gratuito \\
\hline
\end{tabular}




\begin{tabular}{|c|c|c|c|c|c|c|c|}
\hline $\begin{array}{l}\text { Aplicativo } \\
\text { (língua } \\
\text { em que se } \\
\text { encontra) }\end{array}$ & Categoria & Descrição geral & Funcionalidade & $\begin{array}{l}\text { Termos } \\
\text { relacionados } \\
\text { na busca }\end{array}$ & $\begin{array}{l}\text { Público- } \\
\text { alvo }\end{array}$ & $\begin{array}{l}\text { Sistema } \\
\text { operacional }\end{array}$ & Custo \\
\hline $\begin{array}{l}10 \\
\text { My nurse } \\
\text { (português) }\end{array}$ & Cuidado do idoso & $\begin{array}{l}\text { Auxilia o cuidador } \\
\text { de idosos no dia a } \\
\text { dia com o paciente } \\
\text { e ajuda o idoso } \\
\text { nas tarefas diárias }\end{array}$ & $\begin{array}{l}\text { Oferece instruções } \\
\text { para o cuidado } \\
\text { de idosos por } \\
\text { meio de vídeos, } \\
\text { avisa, por meio } \\
\text { de alarme sonoro, } \\
\text { os horários das } \\
\text { tarefas; agenda } \\
\text { dias e horários } \\
\text { de consultas } \\
\text { médicas; salva } \\
\text { um número } \\
\text { para chamadas } \\
\text { urgentes }\end{array}$ & Idoso & $\begin{array}{l}\text { Idosos e } \\
\text { cuidadores } \\
\text { de idosos }\end{array}$ & Android & $R \$ 4,00$ \\
\hline $\begin{array}{l}11 \\
\text { Elderly care } \\
\text { (inglês) }\end{array}$ & Cuidado do idoso & $\begin{array}{l}\text { Ajuda o cuidador } \\
\text { do idoso }\end{array}$ & $\begin{array}{l}\text { Disponibiliza } \\
\text { informações } \\
\text { escritas sobre } \\
\text { saúde e sobre o } \\
\text { cuidar; permite o } \\
\text { compartilhamento } \\
\text { de histórias; e } \\
\text { localiza farmácias } \\
\text { próximas }\end{array}$ & Idoso; elderly & $\begin{array}{l}\text { Familiares e } \\
\text { cuidadores } \\
\text { de idosos }\end{array}$ & Android e iOS & Gratuito \\
\hline $\begin{array}{l}12 \\
\text { Geriatria } \\
\text { (português) }\end{array}$ & Cuidado do idoso & $\begin{array}{l}\text { Aborda temas } \\
\text { relevantes à } \\
\text { saúde do idoso } \\
\text { e aos aspectos } \\
\text { que devem ser } \\
\text { considerados na } \\
\text { hora de escolher } \\
\text { um residencial } \\
\text { geriátrico }\end{array}$ & $\begin{array}{l}\text { Conteúdo e } \\
\text { orientações } \\
\text { escritas e em } \\
\text { vídeos sobre } \\
\text { as principais } \\
\text { emergências } \\
\text { em idosos } \\
\text { e a atuação } \\
\text { adequada para } \\
\text { essas situações; } \\
\text { contato de } \\
\text { clínicas geriátricas } \\
\text { e instituições } \\
\text { de longa } \\
\text { permanência } \\
\text { em Porto Alegre } \\
\text { (RS) por região } \\
\text { (norte e sul), } \\
\text { assim como de } \\
\text { profissionais de } \\
\text { saúde }\end{array}$ & Idoso & $\begin{array}{l}\text { Familiares de } \\
\text { idosos }\end{array}$ & Android & Gratuito \\
\hline $\begin{array}{l}13 \\
\text { Hiring home } \\
\text { caregivers: } \\
\text { family guide } \\
\text { (inglês) }\end{array}$ & Cuidado do idoso & $\begin{array}{l}\text { Destinado a } \\
\text { auxiliar familiares } \\
\text { a entender } \\
\text { os cuidados } \\
\text { necessários para } \\
\text { idosos }\end{array}$ & $\begin{array}{l}\text { Informações } \\
\text { sobre saúde e } \\
\text { envelhecimento, } \\
\text { assim como } \\
\text { orientações de } \\
\text { como encontrar } \\
\text { bons profissionais } \\
\text { que trabalham em } \\
\text { domicílio }\end{array}$ & Idoso & $\begin{array}{l}\text { Familiares e } \\
\text { cuidadores } \\
\text { de idosos }\end{array}$ & iOS & USD 2,99 \\
\hline
\end{tabular}




\begin{tabular}{|c|c|c|c|c|c|c|c|}
\hline $\begin{array}{l}\text { Aplicativo } \\
\text { (língua } \\
\text { em que se } \\
\text { encontra) }\end{array}$ & Categoria & Descrição geral & Funcionalidade & $\begin{array}{l}\text { Termos } \\
\text { relacionados } \\
\text { na busca }\end{array}$ & $\begin{array}{l}\text { Público- } \\
\text { alvo }\end{array}$ & $\begin{array}{l}\text { Sistema } \\
\text { operacional }\end{array}$ & Custo \\
\hline $\begin{array}{l}14 \\
\text { Cuidar } \\
\text { de idosos } \\
\text { (português) }\end{array}$ & Cuidado do idoso & $\begin{array}{l}\text { Conteúdo e dicas } \\
\text { de como cuidar } \\
\text { melhor de pessoas } \\
\text { idosas em situação } \\
\text { de dependência }\end{array}$ & $\begin{array}{l}\text { Informações } \\
\text { escritas sobre } \\
\text { emergências } \\
\text { com em idosos, } \\
\text { medicações, } \\
\text { quedas e } \\
\text { orientações para } \\
\text { cuidadores de } \\
\text { idosos }\end{array}$ & Saúde do idoso & $\begin{array}{l}\text { Familiares e } \\
\text { cuidadores } \\
\text { de idosos }\end{array}$ & Android & Gratuito \\
\hline $\begin{array}{l}15 \\
\text { Cuidar idoso } \\
\text { (português) }\end{array}$ & $\begin{array}{l}\text { Busca de } \\
\text { profissionais de } \\
\text { saúde }\end{array}$ & $\begin{array}{l}\text { Ajuda a encontrar } \\
\text { profissionais } \\
\text { da saúde e } \\
\text { estabelecimentos } \\
\text { que trabalham } \\
\text { com atendimento } \\
\text { aos idosos }\end{array}$ & $\begin{array}{l}\text { Disponibiliza } \\
\text { busca de } \\
\text { profissionais e } \\
\text { serviços voltados } \\
\text { para idosos, } \\
\text { informa sobre } \\
\text { eventos e possui } \\
\text { agenda para as } \\
\text { atividades dos } \\
\text { idosos }\end{array}$ & Idoso & $\begin{array}{l}\text { Idosos e seus } \\
\text { familiares }\end{array}$ & Android e iOS & Gratuito \\
\hline $\begin{array}{l}16 \\
\text { BeFine } \\
\text { (português) }\end{array}$ & $\begin{array}{l}\text { Busca de } \\
\text { profissionais } \\
\text { de saúde e } \\
\text { cuidadores }\end{array}$ & $\begin{array}{l}\text { Ajuda a encontrar } \\
\text { cuidadores } \\
\text { de idosos e } \\
\text { profissionais de } \\
\text { saúde }\end{array}$ & $\begin{array}{l}\text { Disponibiliza } \\
\text { currículos de } \\
\text { profissionais } \\
\text { e áudios de } \\
\text { entrevistas com } \\
\text { eles; permite a } \\
\text { contratação e o } \\
\text { pagamento do } \\
\text { profissional }\end{array}$ & $\begin{array}{l}\text { Idoso; saúde do } \\
\text { idoso }\end{array}$ & $\begin{array}{l}\text { Idosos e seus } \\
\text { familiares }\end{array}$ & Android & Gratuito \\
\hline $\begin{array}{l}17 \\
\text { Easy idoso } \\
\text { (português) }\end{array}$ & $\begin{array}{l}\text { Busca de } \\
\text { serviços de } \\
\text { saúde }\end{array}$ & $\begin{array}{l}\text { Auxilia a busca de } \\
\text { serviços de saúde } \\
\text { e estabelecimentos } \\
\text { para idosos }\end{array}$ & $\begin{array}{l}\text { Auxilia encontrar } \\
\text { serviços e } \\
\text { estabelecimentos } \\
\text { de saúde } \\
\text { relacionados ao } \\
\text { cuidado do idoso } \\
\text { (instituições } \\
\text { de longa } \\
\text { permanência, } \\
\text { associações etc.) } \\
\text { de acordo com } \\
\text { a localização do } \\
\text { usuário }\end{array}$ & Idoso & $\begin{array}{l}\text { Familiares e } \\
\text { cuidadores } \\
\text { de idosos }\end{array}$ & iOS e Android & Gratuito \\
\hline $\begin{array}{l}18 \\
\text { Medsênior } \\
\text { (português) }\end{array}$ & $\begin{array}{l}\text { Busca de } \\
\text { profissionais de } \\
\text { saúde }\end{array}$ & $\begin{array}{l}\text { Auxilia a busca de } \\
\text { profissionais de } \\
\text { saúde }\end{array}$ & $\begin{array}{l}\text { Busca de } \\
\text { profissionais } \\
\text { de saúde } \\
\text { cadastrados, } \\
\text { permitindo a } \\
\text { pesquisa por } \\
\text { localização, } \\
\text { especialidade e } \\
\text { convênio }\end{array}$ & Idoso & $\begin{array}{l}\text { Familiares e } \\
\text { cuidadores } \\
\text { de idosos }\end{array}$ & iOS & Gratuito \\
\hline
\end{tabular}




\begin{tabular}{|c|c|c|c|c|c|c|c|}
\hline $\begin{array}{l}\text { Aplicativo } \\
\text { (língua } \\
\text { em que se } \\
\text { encontra) }\end{array}$ & Categoria & Descrição geral & Funcionalidade & $\begin{array}{l}\text { Termos } \\
\text { relacionados } \\
\text { na busca }\end{array}$ & $\begin{array}{l}\text { Público- } \\
\text { alvo }\end{array}$ & $\begin{array}{l}\text { Sistema } \\
\text { operacional }\end{array}$ & Custo \\
\hline \multicolumn{8}{|c|}{ Aplicativos com informações sobre saúde e cuidados de idosos } \\
\hline $\begin{array}{l}19 \\
\text { Healthy aging } \\
\text { (inglês) }\end{array}$ & $\begin{array}{l}\text { Informativo } \\
\text { sobre saúde e } \\
\text { envelhecimento } \\
\text { saudável }\end{array}$ & $\begin{array}{l}\text { Conteúdo sobre } \\
\text { como ter um } \\
\text { envelhecimento } \\
\text { saudável }\end{array}$ & $\begin{array}{l}\text { Informações } \\
\text { sobre vários } \\
\text { temas ligados ao } \\
\text { envelhecimento } \\
\text { saudável, como } \\
\text { exercício físico, } \\
\text { controle de } \\
\text { doenças, sono, } \\
\text { vitaminas, } \\
\text { estresse, } \\
\text { envolvimento } \\
\text { social, entre } \\
\text { outros }\end{array}$ & Envelhecimento & Idosos & Android & Gratuito \\
\hline $\begin{array}{l}20 \\
\text { Envelhecimento } \\
\text { e saúde } \\
\text { (inglês) }\end{array}$ & $\begin{array}{l}\text { Informativo } \\
\text { sobre saúde e } \\
\text { bem-estar do } \\
\text { idoso }\end{array}$ & $\begin{array}{l}\text { Conteúdo voltado } \\
\text { para um maior } \\
\text { bem-estar do idoso } \\
\text { e manutenção da } \\
\text { saúde ao longo do } \\
\text { envelhecimento }\end{array}$ & $\begin{array}{l}\text { Disponibiliza } \\
\text { vídeos com } \\
\text { conteúdos } \\
\text { relacionados ao } \\
\text { bem-estar e à } \\
\text { saúde }\end{array}$ & Envelhecimento & Idosos & Android & Gratuito \\
\hline $\begin{array}{l}21 \\
\text { AGS GEMS } \\
\text { (American } \\
\text { Geriatrics } \\
\text { Society) } \\
\text { (inglês) }\end{array}$ & \begin{tabular}{|l} 
Informativo \\
sobre saúde e \\
gerenciamento \\
de \\
multimorbidades
\end{tabular} & $\begin{array}{l}\text { Guia com } \\
\text { informações } \\
\text { clínicas sobre } \\
\text { saúde, avaliação } \\
\text { dos idosos e } \\
\text { gerenciamento de } \\
\text { multimorbidades }\end{array}$ & \begin{tabular}{|l} 
Informações \\
escritas da \\
Sociedade \\
Americana de \\
Geriatria
\end{tabular} & Elderly & $\begin{array}{l}\text { Familiares e } \\
\text { cuidadores } \\
\text { de idosos }\end{array}$ & iOS & $\$ 9,99$ \\
\hline $\begin{array}{l}22 \\
\text { Geriatrics at } \\
\text { your fingertips } \\
\text { (inglês) }\end{array}$ & $\begin{array}{l}\text { Informativo } \\
\text { sobre saúde e } \\
\text { tratamento de } \\
\text { condições e } \\
\text { agravos }\end{array}$ & $\begin{array}{l}\text { Informações } \\
\text { e atualizações } \\
\text { sobre avaliações } \\
\text { geriátricas, } \\
\text { tratamentos e } \\
\text { medicamentos }\end{array}$ & $\begin{array}{l}\text { Contém "Geriatria } \\
\text { na ponta do } \\
\text { seu dedo" a } \\
\text { publicação } \\
\text { mais recente } \\
\text { da Sociedade } \\
\text { Americana } \\
\text { de Geriatria, } \\
\text { links para } \\
\text { acessar sites, } \\
\text { instrumentos } \\
\text { de avaliação e } \\
\text { referências da } \\
\text { literatura }\end{array}$ & Saúde do idoso & $\begin{array}{l}\text { Profissionais, } \\
\text { familiares e } \\
\text { cuidadores } \\
\text { de idosos }\end{array}$ & Android e iOS & Gratuito \\
\hline $\begin{array}{l}23 \\
\text { iGeriatrics } \\
\text { (inglês) }\end{array}$ & $\begin{array}{l}\text { Informativo } \\
\text { clínico sobre } \\
\text { doenças, agravos } \\
\text { e imunização }\end{array}$ & $\begin{array}{l}\text { Informações } \\
\text { clínicas da } \\
\text { Sociedade } \\
\text { Americana de } \\
\text { Geriatria }\end{array}$ & $\begin{array}{l}\text { Informações } \\
\text { escritas sobre } \\
\text { medicamentos, } \\
\text { imunização, } \\
\text { quedas, doenças } \\
\text { cardíacas e saúde } \\
\text { mental }\end{array}$ & $\begin{array}{l}\text { Salud de los } \\
\text { ancianos; elderly }\end{array}$ & $\begin{array}{l}\text { Idosos, seus } \\
\text { familiares e } \\
\text { cuidadores, } \\
\text { assim como e } \\
\text { profissionais } \\
\text { geriátricos }\end{array}$ & Android e iOS & $\$ 9,99$ \\
\hline
\end{tabular}




\begin{tabular}{|c|c|c|c|c|c|c|c|}
\hline $\begin{array}{l}\text { Aplicativo } \\
\text { (língua } \\
\text { em que se } \\
\text { encontra) }\end{array}$ & Categoria & Descrição geral & Funcionalidade & $\begin{array}{l}\text { Termos } \\
\text { relacionados } \\
\text { na busca }\end{array}$ & $\begin{array}{l}\text { Público- } \\
\text { alvo }\end{array}$ & $\begin{array}{l}\text { Sistema } \\
\text { operacional }\end{array}$ & Custo \\
\hline $\begin{array}{l}24 \\
\text { Senior Health } \\
\text { Info \& Updates } \\
\text { (inglês) }\end{array}$ & $\begin{array}{l}\text { Informativo } \\
\text { sobre saúde, } \\
\text { serviços e } \\
\text { cuidado do idoso }\end{array}$ & $\begin{array}{l}\text { Informações } \\
\text { sobre saúde e } \\
\text { serviços para } \\
\text { idosos, programas } \\
\text { de assistência ao } \\
\text { idoso, planos de } \\
\text { saúde, vida na } \\
\text { terceira idade, } \\
\text { dentre outros }\end{array}$ & $\begin{array}{l}\text { Disponibiliza as } \\
\text { informações por } \\
\text { meio de artigos } \\
\text { científicos, } \\
\text { matérias e sites }\end{array}$ & $\begin{array}{l}\text { Salud de los } \\
\text { ancianos }\end{array}$ & $\begin{array}{l}\text { Idosos, seus } \\
\text { familiares e } \\
\text { cuidadores } \\
\text { de idosos }\end{array}$ & Android & Gratuito \\
\hline $\begin{array}{l}25 \\
\text { Seniors Health } \\
\text { News (inglês) }\end{array}$ & $\begin{array}{l}\text { Informativo } \\
\text { sobre saúde do } \\
\text { idoso }\end{array}$ & $\begin{array}{l}\text { Notícias e } \\
\text { atualizações sobre } \\
\text { saúde }\end{array}$ & $\begin{array}{l}\text { Contém texto, } \\
\text { notícias, } \\
\text { reportagens } \\
\text { escritas além } \\
\text { de um espaço } \\
\text { para buscar } \\
\text { informações } \\
\text { dentro no } \\
\text { aplicativo e em } \\
\text { um site de busca } \\
\text { da internet }\end{array}$ & Saúde do idoso & $\begin{array}{l}\text { Idosos, } \\
\text { familiares e } \\
\text { cuidadores }\end{array}$ & Android & Gratuito \\
\hline
\end{tabular}

Fonte: Os autores (2017)

Os diversos aplicativos descritos nesta pesquisa, desenvolvidos para beneficiar a saúde e o cuidado de idosos, evidenciam não só o crescente interesse desse grupo populacional por tecnologia e o aumento da oferta de produtos e serviços tecnológicos para eles, mas também pela internet e pelos aplicativos como meios de busca de informações sobre saúde.

Os idosos almejam participar de forma mais efetiva das atividades relacionadas com os artefatos tecnológicos, de modo que, apesar dos empecilhos, estão cada vez mais engajados na descoberta de novas tecnologias ${ }^{3}$. As dificuldades apresentadas pelos idosos, decorrentes da falta de familiaridade com a tecnologia, do medo, da insegurança de manipular dispositivos eletrônicos, da dificuldade visual, motora e de memória e atenção, são compensadas pela motivação, pelo interesse e empenho em aprender a utilizar a internet e os dispositivos eletrônicos ${ }^{17}$. Um dos temas que desperta o seu interesse é a própria saúde. Um estudo com idosos poloneses mostrou que $32 \%$ faziam uso da internet frequentemente, entre os quais $81 \%$ a usavam para obter informações sobre doenças específicas e saúde ${ }^{18}$.

A utilização de ferramentas tecnológicas na área da saúde está em crescente expansão $0^{16}$. Uma das principais vantagens das intervenções em saúde por meio de aplicativos é que elas são facilmente acessíveis e utilizáveis, além de alcançarem diferentes segmentos da população ${ }^{19}$, como o público idoso. Para esse público, os aplicativos podem funcionar como estratégias facilitadoras do autocuidado, da manutenção da autonomia e da independência9.

Para os familiares, que desempenham um papel importante no cuidado de idosos, os aplicativos móveis são uma fonte adicional de informação. Segundo Kim, Powell e Bhuyan ${ }^{20}$, os familiares utilizam a internet para buscar informações médicas mais do que o público em geral; em compensação, utilizam menos os aplicativos. Uma justificativa encontrada por esses autores é que, possivelmente, os cuidadores familiares não tenham tempo suficiente ou encontrem dificuldade de utilizar aplicativos móveis voltados para o cuidado. Fatores sociodemográficos também estão associados ao acesso e uso de aplicativos em saúde. Pessoas com maior grau de escolaridade e convênio médico, por exemplo, têm mais acesso a esses aplicativos. No entanto, a busca 
de informações sobre saúde e cuidado por meio dos smartphones pode ajudar a disseminar informações a familiares e cuidadores com baixo grau de escolaridade, menor renda ou maior dificuldade de acesso a serviços de saúde, tornando-os mais informados e capacitados, melhorando a qualidade e reduzindo os custos do cuidado ${ }^{21,22}$.

Para os profissionais, os aplicativos auxiliam na assistência em saúde, uma vez que sua possibilidade de mobilidade permite que eles se desloquem dentro das instituições em que trabalham, proporcionando mais agilidade e precisão em diversas intervenções, como monitoramento remoto, apoio ao diagnóstico e à tomada de decisão ${ }^{16}$. Um estudo europeu, feito com cuidadores de idosos por meio de vínculo formal, mostrou que as tecnologias de informação e comunicação, como os aplicativos, proporcionam meios efetivos para a administração e o gerenciamento do cuidado ${ }^{23}$.

Nossos resultados mostraram que os aplicativos voltados para a saúde visam à prática de exercício físico, à prevenção ou detecção de quedas e à estimulação cognitiva. De acordo com Wisjman e outros ${ }^{24}$, as intervenções em saúde por meio da tecnologia fornecem novas oportunidades para prevenção do declínio funcional comum no envelhecimento.

Em uma população de adultos e idosos dos Estados Unidos, Martin e outros ${ }^{25}$ mostraram que o grupo que recebia mensagens de texto, via smartphone, para estimular a prática de atividade física, apresentou maior aumento do nível dessa atividade do que o grupo de controle, que não teve esse tipo de interação com o aparelho. Além de estimular e orientar, os aplicativos também podem desempenhar papel de monitoramento da prática de exercício físico por idosos. O aplicativo descrito por Lima e outros ${ }^{26}$ monitora parâmetros fisiológicos, como a frequência cardíaca e o gasto energético, identifica interrupções não esperadas do exercício praticado, como no caso de uma queda, e envia automaticamente uma mensagem para um número do celular previamente definido. O aplicativo visa assim, tornar mais segura a prática do exercício, evitando que os limites fisiológicos sejam ultrapassados e minimizando riscos à saúde do idoso.

A prevenção e detecção de quedas também são importantes para minimizar riscos à saúde dos idosos e, por isso, os aplicativos móveis de smartphones, com seus sensores inerciais integrados, conectividade sem fio e ampla aceitação, tornam-se uma alternativa para as ferramentas convencionais utilizadas com esse objetivo ${ }^{27}$. Outro benefício à saúde dos idosos, encontrado nos aplicativos descritos, é a estimulação cognitiva. Por meio de jogos e entretenimento, eles treinam a memória do idoso, minimizando os efeitos da doença de Alzheimer e melhorando as habilidades cognitivas, a autoconfiança e a qualidade de vida ${ }^{14}$.

Os aplicativos voltados para o cuidado de idosos ressaltam a tendência do desenvolvimento de tecnologias para auxiliar familiares, amigos e profissionais da área de saúde responsáveis pela assistência e cuidado fora do ambiente hospitalar. Com o conhecimento e a observação não só do médico, como também dos familiares, espera-se que padrões de comportamentos e sintomas sejam percebidos precocemente, possibilitando a prevenção ${ }^{28}$.

Estar embasado teoricamente também éimportante para o processo do cuidado e para um envelhecimento mais saudável. Nesse sentido, os aplicativos com informações sobre saúde e cuidado de idosos podem ser um meio facilitador e emancipador para a obtenção de informações sobre saúde ${ }^{18}$. Segundo Pandey e outros $^{29}$, a capacidade que têm os smartphones de fornecerem informações de saúde direcionadas para o paciente rompe barreiras e abre uma era inteiramente nova de comunicação nessa área de conhecimento, embora seja preciso precaução com a qualidade das informações obtidas. O ideal seria a utilização de selos de certificação de conformidade, conferidos por organizações especializadas, como uma forma de garantir algum padrão de qualidade às informações veiculadas em aplicativos e na internet, o que ainda não é nossa realidade ${ }^{30}$.

Nesta pesquisa, os sete aplicativos (do 18 ao 24) listados com informações sobre saúde e cuidado de idosos estão em língua inglesa, mostrando que há necessidade de desenvolvimento de aplicativos nessa 
área em português para que o público que não domina língua estrangeira também possa beneficiar-se, obtendo conhecimentos que repercutem na melhora do cuidado e da saúde dos idosos.

Como mencionado anteriormente, os aplicativos descritos utilizam recursos como jogos, vídeos, imagens e informações escritas para se comunicarem com o público. Quatro dos que têm os idosos como públicoalvo e abordam saúde e cuidado $(19,23,24$ e 25) possuem apenas informações escritas, restringindo o manuseio do aplicativo e a informação a idosos que tenham dificuldade de leitura ou déficit visual. Para evitar essas restrições, os aplicativos devem ter uma interface mais acessível ao idoso, respeitando alguns critérios de ergonomia e usabilidade, devendo ser considerados o tamanho e o tipo de fonte, o tamanho dos ícones, o contraste entre as cores e uma interação mais intuitiva ${ }^{3,31}$.

Diante disso, é relevante e necessário direcionar novos estudos à validação, efetividade e usabilidade dos aplicativos já existentes, de forma que os benefícios propostos pelos aplicativos aos idosos, familiares e profissionais sejam reais e comprovados9.

\section{Considerações finais}

A tendência crescente do emprego de recursos tecnológicos na área da saúde e a expansão do uso de smartphones entre a população idosa contribuem para tornar notável o potencial dos aplicativos móveis destinados à área do envelhecimento. Como reflexo dessa realidade, foram descritos no presente estudo vários aplicativos com diferentes objetivos, funcionalidade, idiomas e valores, voltados para a saúde e o cuidado de idosos.

Tais aplicativos podem ser utilizados como uma ferramenta de monitoramento, informação, promoção de hábitos saudáveis e prevenção de doenças e agravos em idosos. Os seus benefícios se estendem aos familiares, cuidadores e profissionais ligados ao atendimento e cuidado de idoso, mostrando que toda a rede de atenção ao idoso pode ser aprimorada com o uso desse recurso tecnológico, e um melhor atendimento pode ser oferecido, repercutindo positivamente na saúde e qualidade de vida dessa faixa da população.

A necessidade de adaptação dos aplicativos para o público idoso também ficou evidente no presente estudo. Apesar dos benefícios apontados, esses recursos tecnológicos carecem de maiores estudos e investigações, pois, além de conhecimento técnico, énecessário embasamento teórico para o desenvolvimento de interfaces que atendam às necessidades dos idosos, minimizem barreiras de acesso às tecnologias e facilitem a inclusão digital.

\section{Referências}

1. Instituto Brasileiro de Geografia e Estatística (IBGE). Síntese de indicadores sociais: uma análise das condições de vida da população brasileira 2013. Rio de Janeiro; 2013 [citado em 2018 fev. 21]. (Estudos e Pesquisas: informação demográfica e socioeconômica; no 32). Disponível em: http://biblioteca.ibge. gov.br/visualizacao/livros/liv66777.pdf

2. Instituto Brasileiro de Geografia e Estatística (IBGE). Fundo da População das Nações Unidas. (Brasil). Indicadores sociodemográficos: prospectivos para Brasil 1991-2030. São Paulo: Arbeit; 2006 [citado em 2018 fev. 21]. Disponível em: https://ww2.ibge.gov.br/home/estatistica/populacao/projecao da populacao/publicacao UNFPA.pdf

3. Carvalho E, Arantes RC, Cintra ASR. A inserção de idosos do Instituto Henrique da Silva Semente (IHESS) no município de Indaiatuba/SP na era digital: contribuições fisiogerontológicas. Rev Bras Geriatr Gerontol [Internet]. 2016 ago. [citado em 2017 jul. 6];19(4):567-75. http://dx.doi.org/10.1590/1809$\underline{98232016019.150036}$

4. Instituto Brasileiro de Geografia e Estatística (IBGE). Pesquisa nacional por amostra de domicílios: síntese de indicadores 2013. Rio de Janeiro; 2015 [citado em 2018 fev. 21]. Disponível em: http:// biblioteca.ibge.gov.br/visualizacao/livros/liv94414.pdf 
5. Souza JJ, Sales MB. Tecnologias da informação e comunicação, smartphones e usuários idosos: uma revisão integrativa à luz das teorias sociológicas do envelhecimento. R Kairós Gerontol [Internet]. 2016 [citado em 2017 jul. 12];19(4):131-54. Disponível em: https://revistas.pucsp.br/index.php/kairos/article/ view/31957

6. Anderson $\mathrm{M}$, Perrin $\mathrm{A}$. Tech adoption climbs among older adults... [Internet]. Washington, DC: Pew Research Center; 2017 [citado 2017 jul. 12]. Disponível em: https://goo.gl/nAwmjg

7. Instituto Brasileiro de Geografia e Estatística (IBGE). Pesquisa nacional por amostra de domicílios: acesso à internet e à televisão e posse de telefone móvel celular para uso pessoal: 2015. Rio de Janeiro; 2016 [citado em 2017 jul. 12]. Powerpoint slides. Disponível em: https://goo.gl/Liop7s

8. Confederação Nacional de Dirigentes Lojistas (CFNL). Serviço de Proteção ao Crédito (SPC). Dois em cada dez idosos brasileiros usam a internet para fazer compras. São Paulo; 2016 [citado em 2017 jul. 12]. Powerpoint slides. Disponível em: https://goo.gl/vxDY5P

9. Souza CM, Silva AN. Aplicativos para smartphones e sua colaboração na capacidade funcional de idosos. R Saúde Digit Tecnol Educ [Internet]. 2016 jan./jul. [citado em 2017 jul. 12];1(1):06-19. Disponível em: http://periodicos.ufc.br/resdite/article/view/4681/3484

10. Bilotti CC, Nepomuceno LD, Altizani GM, Macuch RS, Lucena TFR, Bortolozzi F, et al. M-Health no controle do câncer de colo do útero: pré-requisitos para o desenvolvimento de um aplicativo para smartphones. Rev Eletron Comun Inf Inov Saúde [Internet]. 2017 abr./jun. [citado em 2017 jul. 13];11(2):1-18. Disponível em: https://goo.gl/34MfAU

11. Corrêa AK, Santos RA, Souza MBM, Clapis MJ. Metodologia problematizadora e suas implicações para a atuação docente e relato de experiência. Educ R [Internet]. 2011 dez. [citado em 201714 jul.];27(3): 61-78. http://dx.doi.org/10.1590/S0102-46982011000300004

12. Tocci FL, Morey MC, Deberry J, Caves KM, Leahy GD, Hall K. Are old adults ready for wireless physical activity tracking devices? A comparison os commonly used tracking devices. J Am Geriatr Soc [Internet]. 2016 jan. [citado em 2017 jul. 15];64(1):226-8. https://doi.org/10.1111/jgs.13895

13. Santos TS, Brito TA, Yokoyama Filho FS, Guimarães FS, Souto CS, Souza SJN et al. Desenvolvimento de aplicativo para dispositivos móveis voltado para identificação do fenótipo de fragilidade em idosos. Rev Bras Geriatr Gerontol [Internet]. 2017 jan./fev. [citado em 2017 jul. 18];20(1):70-6. http://dx.doi. org/10.1590/1981-22562017020.160025

14. Caron J, Biduski D, Marchi ACB. Alz Memory-um aplicativo móvel para treino de memória em pacientes com Alzheimer. Rev Eletron Comun Inf Inov Saúde [Internet]. 2015 abr./jun. [citado em 2017 jul. 19];9(2):1-13. Disponível em: https://goo.gl/EEhfES

15. Mertens A, Brandl C, Mion-Shatz T, Schilick C, Neumann T, Kribben A, et al. A mobile application improves therapy-adherence rates in elderly patients undergoing rehabilitation. A crossover design study comparing documentation via iPad with paper-based control. Medicine [Internet]. 2016 [citado em 2017 jul. 13];95:36. http://dx.doi.org/10.1097/MD.0000000000004446

16. Tibes C, Dias J, Zem-Mascarenhas S. Aplicativos móveis desenvolvidos para a área da saúde no brasil: revisão integrativa da literatura. Rev Min Enferm [Internet]. 2014 abr./jun. [citado em 2017 jul. 19];18(2):471-8. http://www.dx.doi.org/10.5935/1415-2762.20140035

17. Silva A, Felizardo M, Pereira J, Bernardes M, Santana C. Os desafios para o ensino das novas tecnologias para idosos: relato de experiência. Medicina (Ribeirão Preto) [Internet]. 2016 [citado em 2017 nov. 14];49(2):52-3. Disponível em: https://goo.gl/aigWLJ

18. Bujnowska-Fedak MM, Mastalerz-Migas A. Usage of medical internet and e-health services by the elderly. Adv Exp Med Biol [Internet]. 2015 [citado 2017 jul. 19];3:75-80. https://doi.org/10.1007/5584 201474

19. Muellmann S, Forberger S, Möllers T, Zeeb H, Pischle CR. Effectiveness of eHealth interventions for the promotion of physical activity in older adults: a systematic review protocol. BioMed Central [Internet]. 2016 Mar [citado em 2017 fev. 15];5:47. https://doi.org/10.1186/s13643-016-0223-7

20. Kim H, Powell MP, Bhuyan SS. Seeking medical information using mobile apps and the internet: are family caregivers different from general public? Med Syst [Internet]. 2017 [citado em 2017 jul. 12];41:38. https://doi.org/10.1007/s10916-017-0684-9

21. Cotten SR, Gupta SS. Characteristics of online and offline health information seekers and factors that discriminate between them. Soc Sci Med [Internet]. 2004 nov. [citado em 2017 fev. 15]59(9):1795-806. https://doi.org/10.1016/j.socscimed.2004.02.020 
22. Bhuyan SS, Lu N, Chandak A, Kim H, Wyant D, Bhatt J, et al. Use of mobile health applications for health-seeking behavior among US adults. J Med Syst [Internet]. 2016 jun. [citado em 2017 fev. 16];40:153. https://doi.org/10.1007/s10916-016-0492-7

23. Andersson A, Magnusson L, Hanson E. The use of information and communication technologies to support working carers of older people: a qualitative secondary analysis. Int J Older People Nurs [Internet]. 2016 mar. [citado em 2017 jul. 21];11(1):32-43. https://doi.org/10.1111/opn.12087

24. Wijsman CA, Westendorp RG, Verhagen EA, Catt M, Slagboom PE, de Craen AL, et al. Effects of a web-based intervention on physical activity and metabolism in older adults: randomized controlled trial. ] Med Internet Res [Internet]. 2013 [citado em 2017 jul. 21];834:75-80. https://doi. org/10.1007/5584 201474

25. Martin SS, Feldman DI, Blumenthal RS, Jones SR, Post WS, Mckibben RA et al. MActive: a randomized clinical trial of an mhealth intervention for physical promotion. J Am Heart Assoc [Internet]. 2015 [citado em 2017 jul. 22];4(11):1-9. https://doi.org/10.1161/JAHA.115.002239

26. Lima MR, Silva FA, Silva FA, Fabrin APDP, Pazoti MA, Júnior JRG. Utilização dos recursos do IOS para monitorar pessoas de terceira idade na prática de atividades físicas. Colloq Exact [Internet]. 2013 jul./ dez. [citado em 2017 fev.18];5(2):12-29. https://doi.org/10.5747/ce.2013.v05.n2.e057

27. Habib MA, Mohktar MS, Kamaruzzaman SB, Lim KS, Pin TM, Ibrahim F. Smartphone- based solutions for fall detection and prevention: challenges and open issues. Sensors [Internet]. 2014 abr. [citado em 2017 fev. 18];14(4):7181-7208. https://doi.org/10.3390/s140407181

28. Ugulino W, Ferreira M, Velloso E, Fuks. Virtual caregiver: a system for supporting collaboration in elderly monitoring. In: Anais do 90 Simpósio Brasileiro de Sistemas Colaborativos [Internet]. 2012 15-18 out.; São Paulo. São Paulo: Ime/USP; Poli/USP; 2012 [citado em 2017 fev. 20]. p. 43-8. Disponível em: https://goo.gl/HHJJes

29. Pandey A, Hasan S, Dubey D, Sarangi S. Smartphone apps as a source of cancer information: changing trends in health information-seeking behavior. ] Canc Educ. [Internet] 2013 [citado em 2017 fev. 02];28:138-42. https://doi.org/10.1007/s13187-012-0446-9

30. Morettii $F$, Oliveira $V$, Silva $E$. Acesso a informações de saúde na internet: uma questão de saúde pública? Rev Assoc Med Bras [Internet]. 2012 nov./dez. [citado em 2017 jul. 07];58(6):650-8. Disponível em: http://www.scielo.br/pdf/ramb/v58n6/v58n6a08.pdf

31. Tavares M, Souza S. Os idosos e as barreiras de acesso às novas tecnologias da informação e comunicação. Novas Tecnol Educ [Internet]. 2012 [citado em 2017 nov. 07];10(1):1-7. Disponível em: http://www.seer.ufrgs.br/renote/article/viewFile/30915/19244 